\title{
In vivo labeling of cytoplasmic RNA in neurons of the immature brain cortex
}

\author{
JULIO M. AZCURRA*, OTTO Z. SELLINGER AND ANDRÉS E. CARRASCO**
}

(J.M.A. and A.E.C.) Departamento de Biologia, Facultad de Ciencias Exactas y Naturales, Univ. Nacional de Buenos Aires, Buenos Aires (Argentina) and (O.Z.S.) Laboratory of Neurochemistry, Mental Health Research Institute, University of Michigan Medical Center, Ann Arbor, Mich. 48104 (U.S.A.)

(Accepted November 26th, 1974)

Despite much effort, our knowledge of mammalian central nervous system RNA may be said to be inadequate, particularly when we consider the many theories that relate certain types of RNA to memory, learning and other higher brain functions ${ }^{11}$. Two general criticisms of the research carried out to date on CNS RNA are possible. The first is that investigators have failed to discriminate as to the type of cell from which they extracted the RNA prior to analysis - obviously the consequence of the technical difficulties involved in the separation of neurons from glial cells ${ }^{9}$, and the second is that in the few cases where neurons and glial cells were studied separately, only the total and the nuclear RNAs were analyzed. The present report describes a procedure for the isolation of the neuronal cytoplasmic RNA and its application to the measurement of the approximate maturation time of its ribosomal RNA component in 8- and 20-day-old cerebral cortex perikarya. While this work was in progress a report describing the labeling pattern of neuronal and glial cytoplasmic RNA isolated from the whole brain of adult rats has appeared ${ }^{5}$.

Neuronal perikarya were isolated as described previously, except for the following modification: the solution employed for tissue suspension contained $7.5 \%$ polyvinylpyrrolidone (w/v), $10 \mathrm{mMCaCl}$ and $4 \%(\mathrm{w} / \mathrm{v})$ instead of the $1 \%$ bovine serum albumin previously used ${ }^{10}$. With this change in albumin concentration the suspension solution becomes isotonic. The yield and preservation of the perikaryal fraction and its purity were described ${ }^{9,10}$. In each experiment 10 rats were injected intrathecally with $10 \mu \mathrm{Ci}$ of $\left[5-{ }^{3} \mathrm{H}\right]$ uridine (Amersham/Searle, $20 \mathrm{Ci} / \mathrm{mmole}$ ). The neuronai perikarya were suspended in $3 \mathrm{ml}$ of a solution consisting of $0.2 \mathrm{M}$ sucrose- $0.06 \mathrm{M} \mathrm{NaCl}-$ $0.1 M$ Tris-HCl buffer, $\mathrm{pH} 7.6$, and the suspension was homogenized by means of 3 strokes in a glass-teflon loose-fitting homogenizer. The homogenate was centrifuged at $2,000 \times g$ for $10 \mathrm{~min}$ and the supernatant was aspirated and stored in ice. This procedure was repeated and the supernatant pool was brought up to $0.25 \%$ Macaloid (American Tansul Co., Houston, Texas), $0.01 M$ EDTA and $50 \mu \mathrm{g} / \mathrm{ml}$ of polyvinyl

\footnotetext{
* Career Investigator, CONICET.

** Fellow, Instituto Nacional de Farmacologia y Bromatologia.
} 
sulfate. Finally, sodium dodecyl sulfate was added up to a concentration of $1 \%$. This cytoplasmic suspension was extracted with phenol-chloroform $(1: 1)$, according to Perry et al. ${ }^{7}$. The RNA was precipitated by adding 2 vol. of ethanol at $-18^{\circ} \mathrm{C}$ followed by overnight storage at $-18^{\circ} \mathrm{C}$. The precipitated RNA was resuspended and analyzed either by continuous sucrose density gradient sedimentation or by polyacrylamide gel electrophoresis. No evidence of leakage of nuclear RNA into the cytoplasm was uncovered using the above procedures. Other methods tested to disrupt the cells such as exposure to hypotonic media or to $0.5 \%(\mathrm{w} / \mathrm{v})$ Triton X-100 resulted in excessive contamination of the cytoplasmic RNA with nuclear particles. With very short labeling times this leak would represent a serious problem, for even a slight transfer of the highly labeled polydispersed nuclear RNA would easily obscure the early peaks of radioactivity corresponding to the newly synthesized $18 \mathrm{~S}$ and $28 \mathrm{~S}$ rRNAs as they appear in the cytoplasm. The graphs shown in Fig. 1 indicate that in 8-day-old rats the labeling of the cytoplasmic rRNA displayed the following sequence:

A

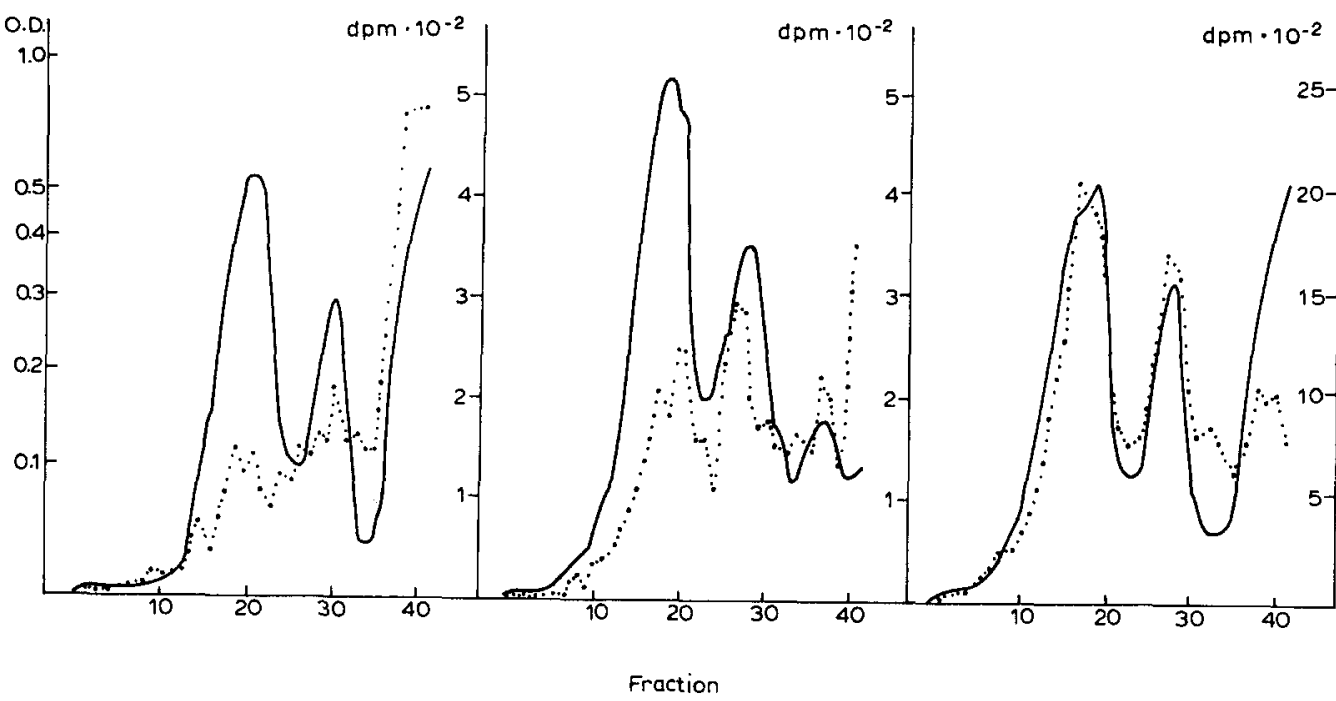

Fig. 1. Continuous densitometric recording and radioanalysis of cytoplasmic RNA from 8-day-old cortical neurons after gradient separation. Each experiment was performed using 10 rats of 8 days of age injected intrathecally with $10 \mu \mathrm{Ci}$ of $\left[5-{ }^{3} \mathrm{H}\right]$ uridine in saline. Neuronal cytoplasm preparation and RNA extraction were as described in the text. RNA was resuspended in $0.02 \mathrm{M}$ Tris- $\mathrm{HCl}$ buffer, pH 7.4;0.1 M NaCl; $0.01 M$ EDTA and was layered on $5-20 \%(w / v)$ continuous sucrose density gradients prepared in the same buffer solution. Centrifugation was for $270 \mathrm{~min}$ at $192,000 \times g$ in a Spinco SW 41 rotor. After piercing the bottom of the centrifuge tube, the absorbance of the effluent was continuously recorded at $254 \mathrm{~nm}$ using an LKB Uvicord II analyzer and 42-44 fractions were collected. These were mixed with a Triton X-100-toluene scintillator ${ }^{4}$ and the radioactivity was counted at about $20 \%$ efficiency. The radioactivity in each vial was corrected for quenching by the channel ratio method. The counting error for each sample was less than $3 \%$. Solid line, O.D.254; dotted line, radioactivity. A: animals killed $30 \mathrm{~min}$ after uridine. B: animals killed $60 \mathrm{~min}$ after uridine. Before loading the RNA was reprecipitated twice in $\mathrm{NaCl}, 0.1 \mathrm{M}-70 \%$ ethanol to eliminate the nucleotides which obscure the slower sedimenting peak of tRNA. C: animals killed $180 \mathrm{~min}$ after uridine. 


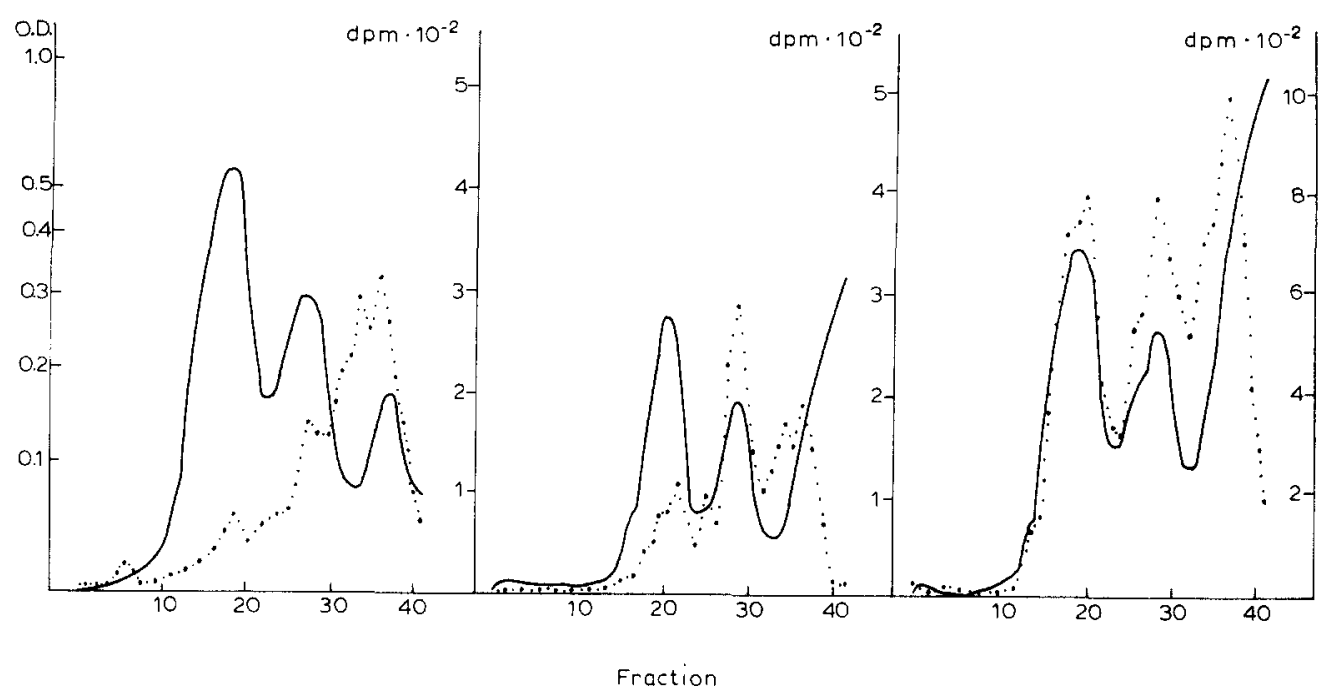

Fig. 2. Continuous densitometric recording and radioanalysis of cytoplasmic RNA from 20-day-old cortical neurons after gradient separation. For procedural details, see legend of Fig. 1. Solid line, O.D.254; dotted line, radioactivity. A: $30 \mathrm{~min}$ after uridine. Before loading the RNA was precipitated as in Fig. 1B. B: 60 min after uridine. C: $180 \mathrm{~min}$ after uridine.

at $30 \mathrm{~min}$ the $18 \mathrm{~S}$ fraction was clearly labeled, while the $28 \mathrm{~S}$ fraction barely began to show radioactivity. At $60 \mathrm{~min}$ both rRNA fractions were labeled but there still was no topographic correlation between the radioactivity and the optical density. This correlation was attained at $180 \mathrm{~min}$. Labeling of 20 -day-old animals disclosed the same pattern. The overall results thus show that: first, as is true for all eukaryotic cells, the initially more highly labeled $18 \mathrm{~S}$ rRNA (Figs. 1 and 2) matures and appears in the cytoplasm as a subribosomal particle ahead of the 28S rRNA; secondly, the times of maturation of rRNA in neurons are very similar to those characteristic of liver cells, but are shorter than those described for the rRNA of HeLa cells ${ }^{7}$; thirdly, the eventual maturation time of neuronal rRNA was virtually identical in both age groups, as indicated by the closeness of the $18 \mathrm{~S} / 28 \mathrm{~S}$ rRNA ratio values at $180 \mathrm{~min}$ (Table I). However, as also shown in Table I, the amount of RNA synthesized by the neuronal perikarya of 8-day-old animals was much greater - about two-fold - under our conditions than that synthesized by the 20-day-old animals. As rRNA constitutes the bulk of the RNA of the neuron, these data suggest that the higher specific radioactivity of the rRNA in the neurons of the younger animals is not the result of a faster processing of the molecules being synthesized but rather the reflection of the processing of a greater number of new molecules. It should also be noted that it is unlikely that the age-related changes in rRNA specific radioactivity are due to variations in the size or the composition of the neuronal soluble RNA precursor pool, for in rat brain these have been shown to range from nil to moderate between 7 and 21 days postnatally ${ }^{6}$. 


\section{TABLE I}

INCORPORATION OF [5-3 H]URIDINE INTO NEURONAL AND WHOLE BRAIN RNA

Animals were injected intrathecally with $10 \mu \mathrm{Ci}$ of $\left[{ }^{[5}{ }^{3} \mathrm{H}\right]$ uridine in saline. RNA was determined quantitatively according to Fleck and $\mathrm{Begg}^{3}$ by measuring the absorbance at $254 \mathrm{~nm}$; subsequently the radioactivity of the same sample was determined. The radioactivity of the discard-fractions (protein, DNA) ${ }^{3}$ was also measured and was always less than $2 \%$ of that of the RNA fraction. Since the total neuronal radioactivity and the radioactivity in the neuronal RNA fraction were identical (see text for details), only the latter values are listed.

\begin{tabular}{|c|c|c|c|c|}
\hline \multirow{3}{*}{$\begin{array}{l}\text { Age of animal and } \\
\text { conditions }\end{array}$} & \multicolumn{4}{|c|}{ Radioactivity in $R N A$} \\
\hline & \multicolumn{2}{|c|}{ Neuronal perikarya } & \multicolumn{2}{|c|}{ Unfractionated brain cortex } \\
\hline & disint. $/ \min / \mu g$ & $18 S / 28 S^{*}$ & disint. $/ \min / \mu g$ & $\%$ of total radioactivity \\
\hline 8 days 30 min pulse & 633 & 2.8 & 212 & 12.9 \\
\hline 8 days $180 \mathrm{~min}$ pulse & 722 & 1.4 & 297 & 21.2 \\
\hline 20 days $30 \mathrm{~min}$ pulse & 322 & 3.9 & 119 & 8.9 \\
\hline 20 days $180 \mathrm{~min}$ pulse & 342 & 1.5 & 154 & 16.0 \\
\hline
\end{tabular}

* Calculated by dividing the disint./min $\times 10^{-2} /$ O.D.254 of the $18 \mathrm{~S}$ peak by the disint./min $\times 10^{-2} /$ O.D.254 of the 28 S peak (Figs. 1 and 2) at the indicated pulse times.

It is interesting to compare the present results with those obtained with normal and regenerating liver cells ${ }^{2}$ : in both cases, despite the different amounts of rRNA maturing per cell per unit of time, the speed of maturation was found to be identical ${ }^{2}$. Our results further revealed that in the neuronal perikarya of both 8- and 20-day-old animals over $99 \%$ of the radioactivity was acid-insoluble, whereas in the unfractionated brain cortex most of it still existed in acid-soluble form by $180 \mathrm{~min}$ (Table I). There are 2 possible explanations for this finding: either the soluble pool of RNA precursors is lost from the neurons during preparation of the perikarya or, in situ, it is very small and thus difficult to detect with the methods used. Since experiments with other small labeled molecules, such as amino acids ${ }^{4}$, have previously permitted the determination of acid-soluble radioactivity in cortical neuronal perikarya isolated by the bulk-isolation procedure utilized in the present study ${ }^{9,10}$, the second alternative is preferred at this time.

The optical density patterns displayed by the cytoplasmic RNA in continuous sucrose gradients (Figs. 1 and 2) showed an asymmetrical shape of the $18 \mathrm{~S}$ and $28 \mathrm{~S}$ rRNA peaks. We established that this asymmetry was not due to ionic conditions, $\mathrm{pH}$ or to the load of RNA placed on the gradients and that it persisted even after several reprecipitations. Analysis of the profile of the phenol-chloroform-extracted RNA on isokinetic gradients also showed definite shoulders of its main components. On the other hand, much more symmetrical peaks of $18 \mathrm{~S}$ and $28 \mathrm{~S}$ rRNA were obtained when neuronal cytoplasmic RNA was extracted with $88 \%$ phenol at $\mathrm{pH} 5.1$ and at $0^{\circ} \mathrm{C}$.

In an attempt to demonstrate the existence of additional species of cytoplasmic RNA we used electrophoresis in polyacrylamide gels, as this technique allowed a better resolution of the RNAs than could be obtained using sucrose density gradient sedi- 

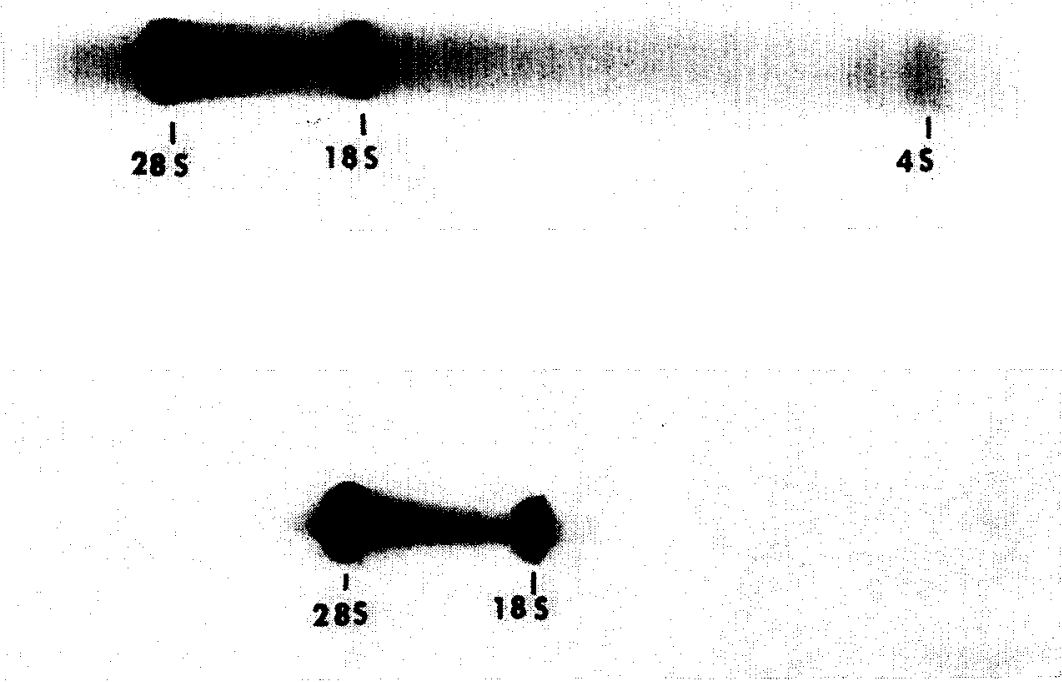

Fig. 3. Gel electrophoresis of cytoplasmic RNA extracted from the neuronal perikarya of 10-day-old animals according to Perry et al. ${ }^{7}$. About $140 \mu \mathrm{g}$ of RNA were run in $2.25 \%$ acrylamide-bisacrylamide gels for $2 \mathrm{~h}$ at $5 \mathrm{~mA}$. The banding pattern was made evident by staining with acridine orange, $2 \%(\mathrm{w} / \mathrm{v})$ in acetic acid, $7.5 \%(\mathrm{v} / \mathrm{v})$. A : photograph of a typical run showing all the cytoplasmic components. B: high contrast picture of the same gel to accentuate the visibility of the bands between $28 \mathrm{~S}$ and $18 \mathrm{~S}$ RNA.

mentation. Fig. 3 shows a typical pattern of the neuronal cytoplasmic RNA extracted with phenol-chloroform at $\mathrm{pH} 7.6$ and room temperature. Several distinct bands other than those of rRNA and of tRNA may be seen, reflecting the existence of RNA species with molecular weights ranging from over $28 \mathrm{~S}$ to under $18 \mathrm{~S}$. Campagnoni et al. ${ }^{1}$ and, more recently, Løvtrup-Rein and Grahn ${ }^{5}$ have suggested that some of these extra species may represent mRNA. We believe that, in addition, some of the extra bands may represent neuronal RNA in association with cytoplasmic ribonucleoproteins of the type described by Samec et al. ${ }^{8}$.

Supported in part by a grant from the United States Public Health Service, NS 06294, to O.Z.S.

1 Campagnoni, A. T., Dutton, G. R., Mahler, H. R., and Moore, W. J., Fractionation of the RNA components of rat brain polysomes, J. Neurochem., 18 (1971) 601-611.

2 Chaudhuri, S., AND Lieberman, I., Time required by the normal and regenerating rat liver cell to make a ribosome, $J$. molec. Biol., 33 (1968) 323-326.

3 FleCK, A., AND BegG, D., The estimation of ribonucleic acid using ultraviolet absorption measurements, Biochim. biophys. Acta (Amst.), 108 (1965) 333-339.

4 Johnson, D. E., AND Sellinger, O.Z., Age-dependent utilization of phenylalanine for the synthesis of neuronal and glial proteins, Neurobiology, 3 (1973) 113-124.

5 Lovtrup-Rein, H., and Grahn, B., Polysomes and polysomal RNA from nerve and glial cell fractions, Brain Research, 72 (1974) 123-136. 
6 Mandel, P., ANd Edel-Harth, S., Free nucleotides in the rat brain during post-natal development, J. Neurochem., 13 (1966) 591-595.

7 Perry, R. P., Latorre, J., Kelley, D. E., and Greenberg, J. R., On the lability of poly-A sequences during extractions of messenger RNA from polyribosomes, Biochim. biophys. Acta (Amst.), 262 (1972) 220-226.

8 Samec, J., Mandel, P., AND Jacob, M., Occurrence of light ribonucleoprotein (RNP) particles in the microsomal fraction of the adult rat brain, $J$. Neurochem., 14 (1967) 889-892.

9 Sellinger, O. Z., And Azcurra, J. M., In N. Marks and R. Rodnight (Eds.), Research Methods in Neurochemistry, Vol. 2, Plenum Press, New York, 1974, pp. 3-38.

10 Sellinger, O. Z., Azcurra, J. M., Johnson, D. E., Ohlsson, W. G., And Lodin, Z., Independence of protein synthesis and drug uptake in nerve cell bodies and glial cells isolated by a new technique, Nature New Biol., 239 (1971) 253-256.

11 Talwar, G. P., In N. E. ANd M. BitTar (Eds.), The Biological Basis of Medicine, Academic Press, New York, 1969, pp. 77-109. 